\title{
Decompensated esophoria and asthenopia correlated with electronic screens overuse in childhood: a case report
}

\author{
Silvia Maddii CO* \\ Orthoptic Unit, Eye Clinic - Neuromusculoskeletal Department, Careggi Hospital, University of Florence, Italy
}

\begin{abstract}
During the last years, the incidence of asthenopia is steadily increasing into the general population due to the concomitant growth and spread of electronic screens. Young people, who often keep their eyes glued to video games, cell phones and computers all day long, even at school, are particularly exposed to eye fatigue. Displays can exacerbate preexisting visual defects or eye motility anomalies, especially if uncorrected refractive errors or labil binocular vision coexist.

Herein, the case of an 11-year-old boy complained about onset of progressive eyestrain and diplopia, especially at near.

A full orthoptic and ophthalmological examination was performed, revealing latent hyperopia, asthenopia and decompensated esophoria associated to transient diplopia.

The aim of this case report is to highlight the possible correlation between electronic devices abuse and binocular imbalance, underlining the possible complications and the orthoptic management.
\end{abstract}

\section{Introduction}

Modern life increasingly demands that we are surrounded by many types of electronic screens in every daily action. Smartphone, in particular, has become the most used device that involving everyone attention during travelling, work or school activities, at home, to dinner table, restroom and even to bed before sleeping [1-2].

Although the intended user can be an adult, or a child, children and adolescents represent the high percentage of smartphone users. With the increasing prevalence of electronic devices, many researchers are investigating the possible visual consequences in using these products. During the past 15 years, specific findings never observed in previous generations were found in younger children; for this reason, it has been recently hypothesized that the prolonged use of electronic screens could potentially be harmful to the developing visual systems of children [3].

The use of handheld smartphones for written communication and their small screens may necessitate close working distances and small text sizes, which can increase the demands placed on accommodation and vergence.

This can result in a symptomatologic complex, called "asthenopia", which includes a variety of symptoms such as headache, burning or itching eyes, dry eye sensation, blurred or double vision. It frequently appears in association with activities requiring near viewing such as reading and writing whereby eye accommodative and vergence processes are more intense [4-6].

An overstraining during near activities and/or a temporary fusion disruption, for longer or shorter periods of time, may lead to decompensation of a pre-existing heterophoria or may result in acute acquired heterotropia [7]. Herein, the case of a child presented with decompensated esophoria associated to asthenopia, where smartphone overuse is thought to be the potential "guilty" of his binocular dissociation.

\section{Case report}

An 11-year-old boy was referred to Careggi Hospital Eye Clinic for blurring and intermittent diplopia from several days. He complained about blurred vision, irritable and tired eyes, with recurrent moments of confusion and double vision, especially for near.

Medical and ocular history was negative. His parents reported an occasionally squint, noted especially when he used his smartphone for several hours.

The child underwent a complete orthoptic/ophthalmologic examination, including corneal reflexes (CR), stereopsis, extraocular motility (EOM), cover test (CT), near point of convergence (NPC), prism fusion range, accommodative convergence/accommodation (AC/A) ratio, measurement of visual acuity (VA) and refraction test.

CR were symmetric for both far and near. Stereoacuity, tested with Titmus test was slightly reduced to 800 seconds of arc (Figure 1). EOM was conserved. CT revealed orthophoria at distance and moderate esophoria $(+10 \Delta)$ with delayed recover, which became an intermittent esotropia $(+20 \Delta)$ on dissociation, with diplopia, at near (Figure 2).

Correspondence to: Silvia Maddii CO, Orthoptic Unit, Eye Clinic Neuromusculoskeletal Department, Careggi Hospital, University of Florence, Italy, E-mail: silvia.maddii@unifi.it

Key words: asthenopia, childhood, decompensated esophoria, diplopia, electronic screens, orthoptic management

Received: February 04, 2018; Accepted: February 27, 2018; Published: February 28,2018 


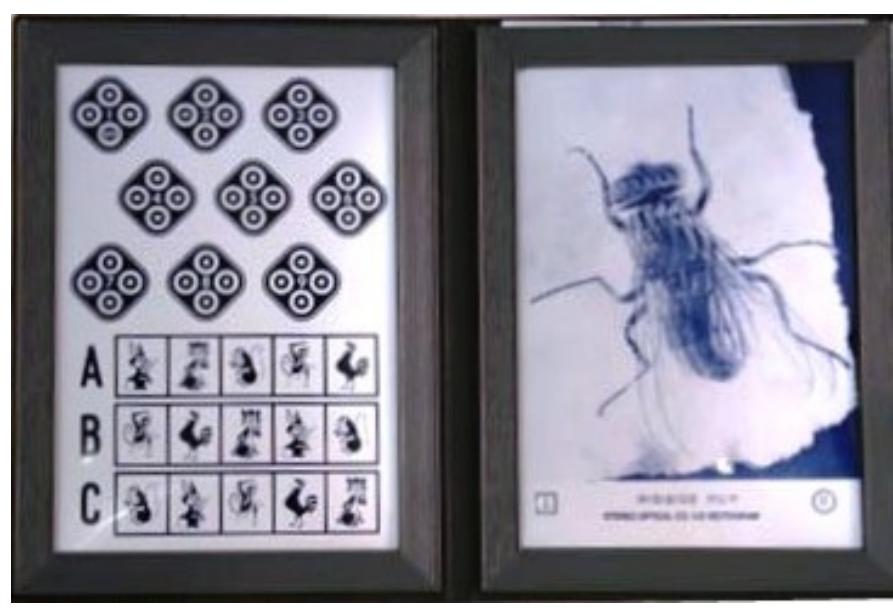

Figure 1. Poor stereopsis of 800 seconds of arc tested with Titmus test (circles N.1).

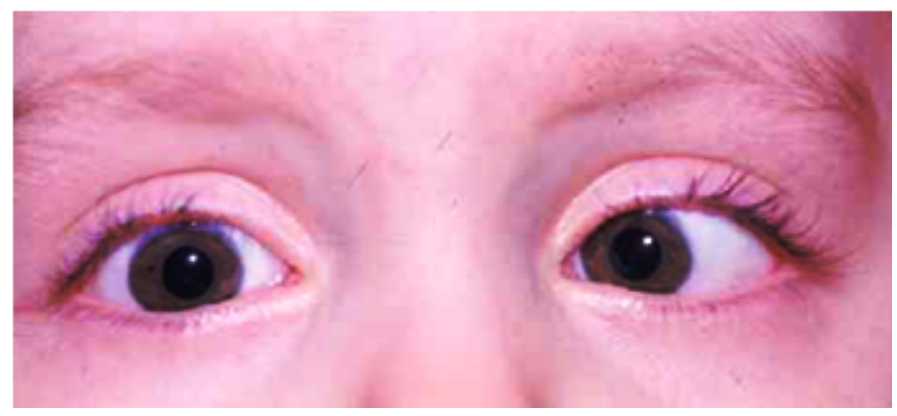

Figure 2. Intermittent esotropia at near after CT prolonged dissociation.

NPC showed a convergence excess and a poor prism fusion range in divergence ( $4 \Delta$ for distance; $8 \Delta$ for near). AC/A ratio was within normal limits.

His uncorrected VA was 20/20 in both eyes, cycloplegia was performed by ophthalmologist using cyclopentolate $1 \%$ eye drops for a more accurate measurement of eventual ametropia, that revealed a latent hyperopia (right eye +1.50 DS; left eye $+2,00 \mathrm{DS}$ ).

After spectacle lenses prescription, orthoptic exercises were conducted as office-based divergence therapy with horizontal prism bar (Figure 3) associated to the minimum amount of relieving Fresnel prism ( $10 \Delta$ base-out splitted into both lenses) that allowed for stable sensory fusion only at near.

Three months after using glasses with Fresnel prisms (progressively reduced from $10 \Delta$ to $6 \Delta$, and finally $4 \Delta$ base-out) in combination with orthoptic rehabilitation, he started improving, becoming symptom free and feeling good.

At 4-month follow-up, also thanks to a more conscious use of smartphone, he showed a complete recovery of binocular vision removing Fresnel prisms and wearing only his spectacle lenses.

\section{Discussion}

Digital devices nowadays influence vision care in everyday life. An intensive use of computers and similar electronic equipment, such as smartphones, e-book readers, video games, have increased the prevalence of asthenopia.

The correlation between asthenopia and digital devices abuse has been widely reported and classified in heterogeneous population into internal ocular symptoms (strain and ache), external ocular symptoms (dryness, irritation, burning), visual symptoms (blur, double vision) and musculoskeletal symptoms (neck and shoulder pain) [1-2].

The major factors are either environmental, for example improper lighting, display position and viewing distance, and dependent on the user's visual abilities, such as uncorrected refractive error, pre-existing phorias or microtropias with poor stereoacuity, oculomotor and accommodative disorders and tear film abnormalities [1-2,5-6]. Several studies have examined the effect of video display terminals on the adult visual system, whereas few studies have been performed on children [3].

This is an important gap in the literature, because when it affects children, visual fatigue may be related to problems involving reading, writing and learning disability, attention, and memory, as well as school performance. Visual fatigue may also indicate the existence of complex conditions such as dyslexia, which require special handling [8].

There are few studies about asthenopia prevalence in elementary school students. In Australia, a large study conducted by Ip et al analyzed 1,448 6-year-old children and found $12.6 \%$ asthenopia rates [9]. Asthenopia prevalence of $23.1 \%$ [10] and $26.4 \%$ [11] was found in two Swedish studies, respectively.

According to a recent research from the University of California, children that have been spending excessive time in front of digital devices and screens could be compromising also their ability to read human emotions [12]. The duration of smart mobile device use has already reached dangerously high levels in the younger generation [13-14].

Bababekova et al demonstrated that the preferred distance for viewing a mobile device $(36.2 \mathrm{~cm})$ was shorter than the typical distance for reading books $(40 \mathrm{~cm})$ and the shorter distance required more accommodation and convergence [15].

Yoshimura et al recently found that the viewing distance in the lying position was shorter than that in the sitting position, considering

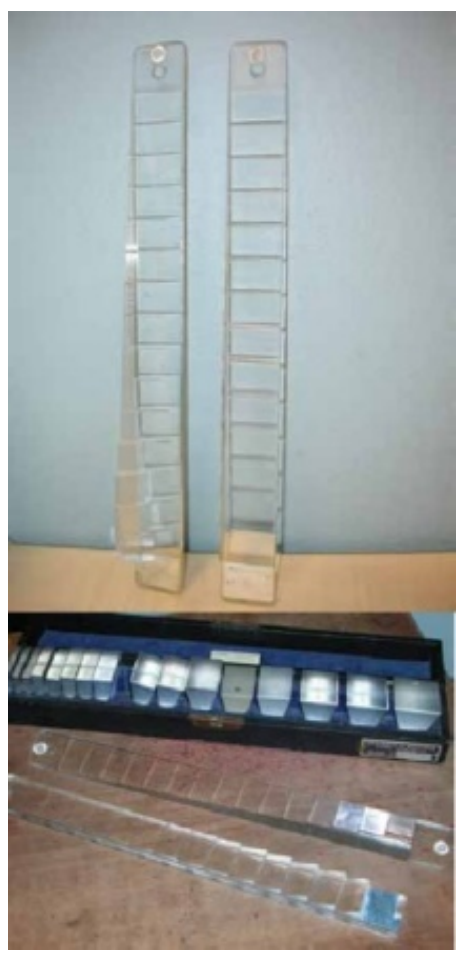

Figure 3. Prism bars used for orthoptic exercises of divergence. 


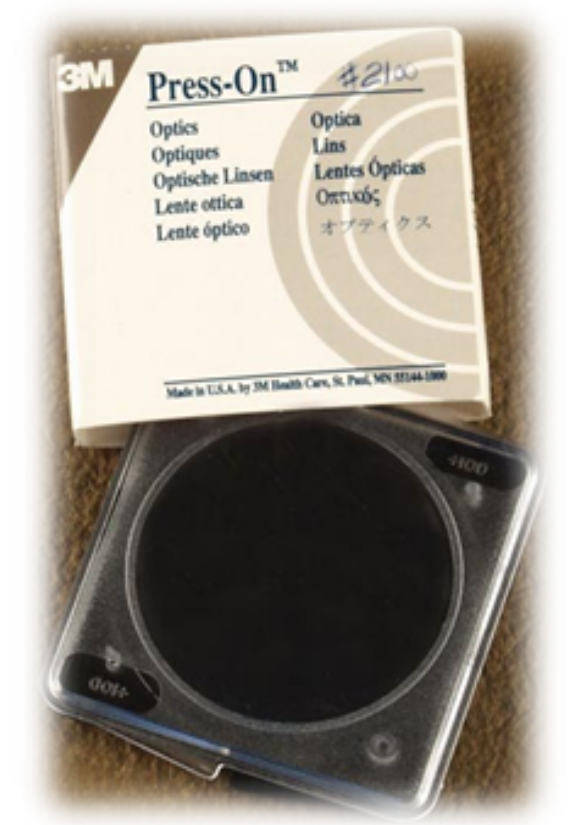

Figure 4. Fresnel Prisms applied on both spectacle lenses to recover binocular vision at near.

smartphones distances correlated negatively with subjective sleep status [16]. An American pilot study compared asthenopia using e-readers VS traditional paper format, constating a significantly higher rate of eyestrain $(\mathrm{p}=0.008)$ and irritation $(\mathrm{p}=0.011)$ in electronic devices group [17].

However, the long-term visual effects of intense and chronic smart mobile device use have not been extensively investigated. The possible ocular health issues caused by intense smart mobile device use may not be confined to ocular surface problems such as dry eyes and tear dysfunction but may also affect the neuronal networks of the retina [18].

\section{Conclusion}

These findings conclude that overusing smartphones and e-devices may induce increased levels of irritation, eyestrain and decompensate etherophories, especially in predisposed subjects. Specifical risk factors, etiology, and potential remedial interventions deserve to be further investigated.

However, the central points for visual prevention are a conscious use of digital displays, taking frequent breaks, and an appropriate application of ophthalmic lenses, when indicated. In case of severe and persistent symptoms, a correct assessment of ocular motility disorders with a rapid orthoptic/ophthalmological intervention can help to correct and minimize the asthenopic effects. The take-home message of this research is that prevention make a huge difference in safeguarding eye and visual health.

\section{References}

1. Rosenfield M (2011) Computer vision syndrome: a review of ocular causes and potential treatments. Ophthalmic Physiol Opt 31: 502-515. [Crossref]

2. Kim DJ, Lim CY, Gu N, Park CY (2017) Visual Fatigue Induced by Viewing a Tablet Computer with a High-resolution Display. Korean J Ophthalmol 31: 388-393. [Crossref]

3. Rechichi C, De Mojà G, Aragona P (2017) Video Game Vision Syndrome: A New Clinical Picture in Children? J Pediatr Ophthalmol Strabismus 54: 346-355. [Crossref]

4. Manuel AP, Vilela MAP, Castagno VD, Meucci RD, Fassa AG (2015) Asthenopia in schoolchildren. Clinical Ophthalmology 1595-1603. [Crossref]

5. Lee HS, Park SW, Heo H (2016) Acute acquired comitant esotropia related to excessive Smartphone use. BMC Ophthalmology 16:37. [Crossref]

6. Long J, Cheung R, Duong S, Paynter R, Asper L (2017) Viewing distance and eyestrain symptoms with prolonged viewing of smartphones. Clin Exp Optom 100: 133-137. [Crossref]

7. Burian HM, Miller JE (1958)Comitant convergent strabismus with acute onset. $A m J$ Ophthalmol 45: 55-64. [Crossref]

8. Vilela MA, Pellanda LC, Fassa AG, Castagno VD (2015) Prevalence of asthenopia in children: a systematic review with meta-analysis. J Pediatr (Rio J) 91: 320-325. [Crossref]

9. Ip JM, Robaei D, Rochtchina E, Mitchell P (2006) Prevalence of eye disorders in young children with eyestrain complaints. Am J Ophthalmol 142: 495-497. [Crossref]

10. Abdi S (2007) Asthenopia in schoolchildren. [Thesis]. Stockholm: Karolinska Institute 59.

11. Sterner B, Gellerstedt M, Sjöstrom A (2006) Accommodation and the relation $\urcorner$ ship to subjective symptoms with near work for young school children. Ophthalmic Physiol Opt 26: 148-155. [Crossref]

12. Uhls YT, Michikyan M, Morris J, Garcia D, Small GW, et al. (2014) Five days at outdoor education camp without screens improves preteen skills with nonverbal emotion cues. Computers in Human Behavior 39: 387-392.

13. Haug S, Castro RP, Kwon M, Filler A, Kowatsch T, et al. (2015) Smartphone use and smartphone addiction among young people in Switzerland. J Behav Addict 4: 299-307. [Crossref]

14. Kim J, Hwang Y, Kang S, Kim M, Kim TS et al. (2016) Association between exposure to smartphones and ocular health in adolescents. Ophthalmic Epidemiol 23: 269-276. [Crossref]

15. Bababekova Y, Rosenfield M, Hue JE, Huang RR (2011) Font size and viewing distance of handheld smart phones. Optom Vis Sci 88: 795-797. [Crossref]

16. Yoshimura M, Kitazawa M, Maeda Y, Mimura M, Tsubota K1, et al. (2017) Smartphone viewing distance and sleep: an experimental study utilizing motion capture technology. Nat Sci Sleep 9: 59-65. [Crossref]

17. Maducdoc MM, Haider A, Nalbandian A, Youm JH, Morgan PV, et al. (2017) Visual consequences of electronic reader use: a pilot study. Int Ophthalmol 37: 433-439. [Crossref]

18. Moon J, Yun J, Yoon YD, Park SI, Seo YJ, et al. (2017) Blue light effect on retina pigment epithelial cells by display devices. Integr Biol (Camb) 9: 436-443.

Copyright: (C2018 Maddii SCO. This is an open-access article distributed under the terms of the Creative Commons Attribution License, which permits unrestricted use, distribution, and reproduction in any medium, provided the original author and source are credited. 